\title{
Fitting as a temporal sensemaking process: shifting trajectories and stable themes
}

Article

Accepted Version

Jansen, K. J. and Shipp, A. J. (2019) Fitting as a temporal sensemaking process: shifting trajectories and stable themes. Human Relations, 72 (7). pp. 1154-1186. ISSN 1741-282X doi: https://doi.org/10.1177/0018726718794268 Available at https://centaur.reading.ac.uk/78302/

It is advisable to refer to the publisher's version if you intend to cite from the work. See Guidance on citing.

To link to this article DOI: http://dx.doi.org/10.1177/0018726718794268

Publisher: Sage

All outputs in CentAUR are protected by Intellectual Property Rights law, including copyright law. Copyright and IPR is retained by the creators or other copyright holders. Terms and conditions for use of this material are defined in the End User Agreement.

www.reading.ac.uk/centaur

\section{CentAUR}


Central Archive at the University of Reading

Reading's research outputs online 


\title{
FITTING AS A TEMPORAL SENSEMAKING PROCESS: SHIFTING TRAJECTORIES AND STABLE THEMES
}

\begin{abstract}
This study identifies several mechanisms and the overall process by which individuals understand their evolving fit with their work environment. Prior person-environment research has emphasized one-time quantitative assessments of fit, primarily as new entrants enter their work environment. In this study, we employed a qualitative approach to investigate the following question: how do long-tenured professionals make sense of fit over time? Three key findings emerged from the fit-related histories we collected. First, we discovered four prototypical fit trajectories, which were constructed from temporal comparisons with past, present, and future fit, and employed to make momentary sense of events occurring in the work environment. Second, we identified two fit processes that played out over time: a slow accumulation journey and a sudden identity-threat journey. Third, we found that individuals' set of fit experiences was explained by one of four enduring fit themes, explaining their pattern of fit experiences over time and their reaction to misfit. Most surprising was the significant turnover among our long-tenured participants in the year or so following our interviews. Our findings break from traditional thinking about fit as predicting outcomes in the moment, to fitting as both a journey and a retrospective and prospective process of sensemaking.
\end{abstract}

Keywords: person-environment fit, misfit, temporal, time, process, sensemaking, qualitative, identity 
After reading [IBM CEO Rometty's open letter in support of presidential candidate Trump], Elizabeth did some soul searching. One might argue she was questioning both her personal purpose (what am I here for, who am I, and how am I going to show up every day at work?) as well as her organization's purpose... That very day...Elizabeth scheduled a meeting with her supervisor and put in her notice.

Pontefract (2016)

There is nothing constant but change. Individuals experience countless changes in their jobs and organizations due to a myriad of events including new staff and reporting structures, downsizing, and leadership changes. Further, individuals themselves may change as the desire for status, pay, or achievement in one's early career may later shift to stronger desires for achieving work-life balance or developing others (cf. Deci and Ryan, 2000; Isabella, 1990; Sullivan, 1999). With the passage of time, it is inevitable that individuals experience changing work and personal circumstances that can make them a poor fit in their work environment (i.e., person-environment fit; Kristof, 1996). Sometimes, as the opening quote suggests, a single event can even introduce such clear misfit that individuals feel abruptly pushed out of the organization after questioning whether they fit the new circumstances and the future changes they bring.

With all the changes that individuals experience and the amount of contemplation and adaptation they necessarily require, it is surprising that research on person-environment (P-E) fit has primarily viewed fit in the current moment (Shipp and Jansen, 2011). In the quote below, Chet (a pseudonym for one of our study participants) acknowledged the changes in fit that occurred with the passage of time:

Now, you may be talking to me in a year or two and I may say, my gosh, I had it so well back there, what was I thinking?...Gosh, the fit changes every day. The fit changes with every person that's hired. Every little organization change, the fit gets altered. Sometimes the hand doesn't fit in the glove anymore and it's time to find a new glove.

His comment also illustrates the temporal character of fit in the current moment: anticipation of future fit ('in a year or two') and a retrospective comparison of fit in the past ('I had it so well back there'). As organizational members ourselves, we may have an innate ability to make sense of and give meaning to our fit over time, but as researchers, we know little about the theoretical mechanisms driving when and how individuals engage in it.

Understanding how individuals make sense of fit is important because the ability to weather fluctuations in P-E fit can help to sustain long-term tenure (cf. Ng and Feldman, 2010), 
allowing organizations to avoid costly turnover of talent during turbulent times (cf. Bentein et al., 2005; Castrogiovanni, 2002). And yet, the empirical P-E fit research to date has given only limited attention to the temporal nature of fit, particularly as individuals and their environments change. We consider this an excellent opportunity to extend P-E fit research in these directions, answering repeated calls for research on the temporal nature of fit (e.g., Caplan, 1983; Judge, 2007; Shipp and Jansen, 2011).

As such, our research theoretically departs from the traditional fit literature in three significant ways. First, our study provides a rich, qualitative exploration of how long-tenured professionals holistically and subjectively make sense of fit. Our approach stands in stark contrast to the predominance of research emphasizing specific dimensions of the environment (cf. Kristof-Brown et al., 2005). This focus has advanced our quantitative understanding of fit, but has potentially limited our ability to fully understand how professionals subjectively experience fit, particularly as time passes and change occurs. In this study, we embrace a holistic and subjective view of fit and employ a qualitative methodology, which provides an off-diagonal research opportunity ${ }^{1}$ (Edmondson and McManus, 2007) that is useful in developing new theory.

Second, our study is decidedly temporal, incorporating both clock time and psychological time. Clock (objective) time addresses the actual passage of time, whereas psychological (subjective) time addresses perceptions of time in the current moment, including retrospections and anticipations (McGrath and Rotchford, 1983). Looking at time in both objective and subjective ways contradicts the vast majority of fit research that has examined fit in the current moment alone, missing the more complex ways in which people consider fit in relation to time. Even as fit studies have begun to emerge addressing clock time (e.g., Boon and Biron, 2016; Gabriel et al., 2014), the psychological aspects of time have been virtually ignored (cf. Caplan, 1983). In this study, we consider both psychological and clock time to gain temporal insights into fit beyond the current moment.

\footnotetext{
${ }^{1}$ An off-diagonal research opportunity occurs when either a "nascent" theory is matched with quantitative measures or a "mature" theory is matched with qualitative methods (Edmondson and McManus, 2007, p. 1168).
} 
Third, we adopt a process lens in our approach, allowing individuals to explain how they make sense of fit over time. This approach stands in contrast to prior fit research that rarely explains the process by which fit changes or how individuals maintain their fit over time. Although notable, we see only a few conceptual rather than empirical, exceptions to this approach (Dawis and Lofquist, 1984; Kammeyer-Mueller, 2007; Schneider, 1987; Shipp and Jansen, 2011). Thus, our study shines an empirical light on the process of fitting at work.

In sum, to address the lack of attention to the process by which individuals make sense of fit over time, we conducted an inductive study of how long-tenured professionals understand and give meaning to their fit over the passage of both subjective and objective time. Our initial research question was “How do long-tenured professionals make sense of fit over time?", which offered many insights into the experience of fit as we will discuss. However, we found insights that we had not anticipated, such as the tight coupling between perceptions of fit and identity. Therefore, to orient the reader in advance of our findings, we briefly review the fit literature as well as research at the nexus of sensemaking and identity.

\section{Conceptual background}

Person-environment fit research has experienced significant progress since the initial ideas about fit (Murray, 1938) were introduced. Lewin's (1943) classic statement, that behavior is a function of the environment and the person, led to a plethora of studies showing that there are numerous ways to consider the compatibility or fit between a person and his or her environment (Kristof, 1996; Kristof-Brown et al., 2005). These studies of P-E fit vary in their content, whether they address perceived and/or actual (objective) experiences of fit, fit with different aspects of the environment (e.g., individuals, jobs, groups, organizations), or fit based on various dimensions upon which comparisons are made (e.g., values, personality, needs, abilities, or vocational interests).

In the last twenty years, a steady stream of predominantly quantitative research has blossomed in the field of P-E fit, particularly in terms of construct development (e.g., Edwards et al., 2006; Kristof, 1996) and more precise data analytic techniques (cf., Edwards, 1994, 2002). 
However, despite the extensive and sophisticated ways in which researchers have studied fit, we identify three considerations that have largely been underdeveloped in empirical research to date: a holistic and subjective view of fit, the role that time plays in how fit is understood and acted upon, and the process by which fit changes.

First, the preponderance of empirical fit studies to date have focused on measuring specific aspects of the work environment (e.g., person-organization, P-O; person-job, P-J; person-group, P-G; person-supervisor, P-S). These studies have demonstrated that congruence between an individual and a particular aspect of the environment predicts many important outcomes, such as satisfaction, strain, performance, and turnover, among others (cf. KristofBrown et al., 2005). To date, these quantitative studies of P-E fit have improved the precision of measurement and provided extensive quantitative evidence that the various aspects of fit are important predictors of work-related outcomes. Yet, some have suggested that there is little to be learned about fit if this trend toward greater specificity continues (Harrison, 2007). Whereas robust quantitative measures of the dimensions of fit offer incredible precision in distinguishing precise aspects, they fail to capture how people characterize and understand their fit holistically (i.e., where multiple aspects of fit interact or combine to form an overall subjective assessment; cf. Cable and DeRue, 2002; Jansen and Kristof-Brown, 2006; Wheeler et al., 2005).

In support of holistic fit, a few studies have examined multiple aspects of fit simultaneously, finding that single aspects of fit do not operate in isolation from the others (cf. Harold et al., 2016; Kristof-Brown et al., 2002; Lauver and Kristof-Brown, 2001). Other studies have investigated the form of the relationship between individual aspects of fit and holistic fit, specifically examining whether the various dimensions reflect (i.e., a superordinate model) or form (i.e., an aggregate model) overall fit (Chuang et al., 2016; Darrow and Behrend, 2017). Results regarding the nature of the overall fit construct have been mixed, suggesting the need for further research. In addition, whereas the above studies have focused on quantitative measures, we were quite interested in qualitatively tapping individuals' unprimed responses to a holistic fit question (i.e., do you fit?), to understand how they cognitively formed their response. 
Second, most fit research to date tends to examine fit in the current moment (Jansen and Shipp, 2013). Such an emphasis on snapshots of fit (cf. Kristof-Brown and Jansen, 2007) may miss the more complex ways in which people consider fit in relation to time. Even when the passage of clock time has been considered, such as Boon and Biron's (2016) recent examination of P-O and P-J fit measures separated by one year or Gabriel et al.'s (2014) repeated daily measures of P-O and P-J fit for two weeks, a consideration of psychological time (e.g., retrospections and anticipations) has been notably absent in the empirical literature (cf. Shipp and Cole, 2015). This is surprising given that psychological time was prominent in early fit theorizing (Lewin, 1943, 1951; Murray, 1938), as well as revisited as a conceptual model of retrospected and anticipated fit (Caplan, 1983) and further developed using a narrative lens (Shipp and Jansen, 2011). We were therefore highly motivated to incorporate both clock time and psychological time in our study, because both are essential for understanding how individuals make sense of their unfolding fit.

Finally, although the very earliest scholars suggested that fit builds and unfolds over time, the majority of research to date has said little about the complex ways that people experience the process of change in fit. Further, what has been done in this area has been predominantly conceptual rather than empirical. For example, the Attraction-Selection-Attrition framework (ASA; Schneider, 1987) argued that people are drawn to, selected by, and remain in organizations with similar others, resulting in homogeneity over time. In addition, the theory of work adjustment (Dawis and Lofquist, 1984) suggested that individuals engage in a process to achieve correspondence with their work environment. Finally, fit narrative theory (Shipp and Jansen, 2011) proposed that individuals craft (and recraft) narratives of fit to understand changes within themselves and the environment.

Beyond these important conceptual works, we are aware of only two recent studies (both qualitative) that have shed light on how misfit unfolds. First, Klag et al. (2015) found that iterative P-E fit assessments, triggered by external events, taking stock, or emotions welling up, were a prevalent feature in the process by which individuals contemplated leaving their 
organization. The study also identified four evolving story lines, including reconciling incongruence, which played out over multiple iterations and episodes. However, we note that this model primarily focused on the contemplation of turnover rather than making sense of one's fit in the current role. Second, Follmer et al. (2018) used two separate qualitative samples to explore (1) how people became aware of misfit and (2) the strategies they employed to address misfit over a two-month period. The study found that as misfit becomes salient, individuals employed one or more coping strategies, including leaving or attempting to resolve misfit by changing themselves or their work environment. Combined, these empirical studies provide insight into two process aspects of fit: triggering events generating thoughts of fit, and a myriad of coping strategies individuals engage in to address misfit. However, even with these theoretical and emerging empirical developments, there is much more to be done to improve our understanding of how fit unfolds. Perhaps most important, we do not know the cognitive processes individuals may engage in as misfit accumulates or is resolved. As a result, we do not know how long people may endure misfit before reaching a breaking point. By examining how people make sense of fit and misfit as events occur and time passes, we provide greater insight into the mechanisms associated with the fit journeys individuals engage in to navigate through (mis)fit experiences.

In summary, we find great promise in the fit developments reviewed above, but we have also outlined a significant black box in our understanding of fit that we now formalize. Based on the research reviewed above, the P-E fit process includes events (e.g. job-entry, promotion, supervisor change) that trigger P-E fit assessments; the resulting stress of perceived or actual misfit necessitates coping and adaptation, which then influences various outcomes (e.g., turnover). While these building blocks have been well-studied individually, the psychological and temporal process by which people think about fit has been empirically ignored. We therefore examine how individuals psychologically make sense of fit both in the moment and with the passage of time.

Because we examined fit over time, a cognitive sensemaking perspective (i.e., individual cognition to understand oneself and situations; Sandberg and Tsoukas, 2015; Weick, 1995) 
became a prominent lens for understanding how individuals gave meaning to their fit experiences. A sensemaking perspective is an inherently temporal and ongoing process whereby cues that are discrepant from expectations are noticed, interpreted, given meaning, and enacted in narrative and dialog (cf. Currie and Brown, 2003). Although historically viewed as a retrospective activity (Maitlis and Christianson, 2014), recent research asserts that sensemaking also may be prospective, incorporating past, present and future (Gephart et al. 2010; Stigliani and Ravasi, 2012). Further, sensemaking is also tied to identity in that who people are shapes what they enact and how they interpret events (Watson, 2009), which emerged as more important during our data analysis than we had originally anticipated. A threat to one's current or future identity triggers strong emotions as one grapples with the question, 'who am I now?' (Maitlis, 2009), which can initiate sensemaking to understand and alleviate a perceived threat (Weick, 1995). As we advanced our use of the sensemaking perspective, this broader identity-infused, retrospective and prospective process, became an important lens for understanding our findings and developing our contribution to a temporal and processual theory of fitting over time.

\section{Method}

To explore our research question, we conducted a qualitative study of professionals with long-term tenure. We also adopted a "completely temporal” view (Shipp and Cole, 2015, p. 249) emphasizing both subjective (i.e., psychological) time and objective (i.e., clock) time. We examined fit in four temporal ways, considering how individuals: (1) made sense of their fit in the current moment, (2) considered retrospected and anticipated fit across psychological time, (3) recounted (in the moment) fit experiences that had occurred over clock time, and (4) revised and changed these thought processes with the actual passage of time (i.e., clock time between the first interview and follow-up interview).

\section{Informants}

To address our research question, we selected mid-career, long-tenured professionals between the ages of 35 and 55 (based on 2012 Bureau of Labor Statistics data showing median tenure of 5.3 years for those 35-45 years old, and 7.8 years for those $45-55$ years old), with at 
least 9 years of work experience in their current organization (i.e., the establishment stage of their career; Hall, 1976) The middle of one's career is an under-researched phase of the overall fit experience (Jansen and Kristof-Brown, 2006), yet it is ideal for exploring how individuals conceptualize their fit overall, independent of the strong cues provided when starting or finishing a career. Thus, our initial rationale was to recruit established individuals who were likely to have a richer and more salient set of current and past fit experiences.

In addition to the above age and tenure parameters, we sought individuals who had experienced change during their tenure, whether the changes were personal, organizational, or both. We reasoned that the more change individuals had previously experienced or were currently facing, the more likely they were to have experienced changes in their fit. The prevalence of change would suggest a relatively more volatile environment, which provides a dynamic context for recollecting and processing past experiences, allowing us to identify the mechanisms that enabled them do so. We initially recruited participants by tapping into our personal and professional networks, finding individuals meeting our criteria or obtaining chain referrals from our participants for others (Patton, 1990). We also made a conscious effort to include participants across a variety of industries, and companies of different sizes and types (public/private and profit/non-profit) to be representative of long-tenured professionals and to increase potential variety in fit experiences for theory building.

During data analysis, as particular questions arose or as gaps in our understanding emerged, we theoretically sampled three additional sets of individuals. Specifically, we interviewed three relatively inexperienced individuals ('newbies' aged 22-25) and three nearing retirement ('seniors' aged 60-65) to explore the relative emphasis on past, current, and future fit experiences. In addition, we interviewed three individuals who fit our original criteria for age and total experience but had relatively short tenure in their current organization ('job hoppers' with 1-5 years tenure) to explore how their understanding of fit might differ from those who were more temporally embedded in their work environments. These theoretical samples allowed us to further refine the emerging categories within our purposive sample. 


\section{Data collection}

We employed a topical life history method to gather data (cf. Miles and Huberman, 1994). Topical life histories explore individuals' experiences and interpretations of a particular context (i.e., their fit within their work environment), and the factors affecting it (Taylor and Bogdan, 1984). In general, sharing these experiences helps individuals to understand events that unfold over time (e.g., Ibarra and Barbulescu, 2010; McAdams, 1993), and highlights the selection, sequencing, and significance of those events (Polkinghorne, 1988; Riessman, 2008).

We combined the topical life history approach with elements of McAdams' (1988) life story interview method, by emphasizing a selective recounting of past, present, and future fit. We followed Shipp and Jansen's (2011) in medias res ordering (beginning with present fit, then retrospections about past fit and anticipations of future fit) rather than McAdams' chronological ordering because we were particularly interested in how individuals might describe their current fit without first making the past salient. We also attended to any triggering events, the broader setting in which they occurred, and how events or situations unfolded. Our interview protocol is available upon request. We initially conducted 15 interviews, coded and analyzed them, and then conducted eight additional interviews to further explore emerging themes until we reached theoretical saturation. When combined with the nine interviews comprising the theoretical sample, this ultimately yielded a total of 32 topical life histories. Interviews were 43 minutes on average (ranging from 25-75 minutes), which represented 780 pages of transcribed text.

We also reconnected with participants over time. Initially, we returned to some participants for clarification of the transcripts or as questions in our coding structure arose (Mishler, 1986). We also obtained updates on their employment status as time passed. Finally, we conducted follow-up interviews 12 to 18 months after our initial interview with equal numbers of participants (7 each) who had reported no significant change, changed jobs or supervisors, or changed organizations. We included both the purposive and theoretical samples for this analysis because our interest was on these different outcome states. Participant characteristics, including status changes and second interviews, are reported in Table 1. 
--- Insert Table 1 about here ---

\section{Data analysis}

We analyzed these fit-related histories using constructivist grounded theory, which assumes that the researcher and participants co-produce meaning as the researcher interacts with participants to interpret and describe their accounts (Charmaz, 2000). The authors collaboratively coded the majority of the data, meaning that we were physically collocated, sharing our understanding and interpretations, jointly developing a code book, and questioning assumptions (Saldana, 2009). We used open-coding of all transcripts, forcing us to stay close to the data. We refined the coding labels, eliminated redundant ones, and made theoretical side-notes for later analysis. We also created short characterizations of each informant, made notes of sequences of events, and documented influential elements from the interviews (based on code prevalence). Throughout our process, we continuously revisited both the audio recordings and transcripts, refining code meaning and identifying additional codes or categories.

Once our coding structure was stabilized, the first move toward theory was initially completed using mind-mapping with flip charts, which were displayed around the room as we iterated between data and codes and emerging categories. We also taped a small note in the center of the wall with the words 'What are we missing?' to encourage us to question and doubt our initial moves toward theory (Locke et al., 2008). We developed a preliminary process model from the codes and categories (coding tables are available upon request), paying particular attention to when thoughts of fit were initiated. We then refined and revised this model by examining code interdependencies and causal links the respondents made. We shared several iterations of interim theorizing in both internal research meetings and at various conferences. In the sections below, we also include excerpts from the interviews to allow the reader to assess the credibility and reliability of our analysis (Lincoln and Guba, 1986).

\section{Findings}

Given our interest in understanding fit in terms of time and process, we organized our findings in a temporal manner, viewing individual assessments in four distinct ways: (1) current 
fit, (2) fitting in psychological time (i.e., retrospected and anticipated fit), (3) fitting across

recounted clock time (i.e., fit themes over the recollected passage of time), and (4) fitting across actual clock time (i.e., stability versus change over the actual passage of time). We present each in turn.

Assessment of current fit

We first examined participants' responses both in terms of their subjective characterization of current fit and their constructed answer to our initial question, "Do you fit?". In terms of how they characterized current fit, some participants described fit as being salient to a particular aspect of the organization (e.g., 'a company that really aligns with my...belief system' - P-O fit). Others emphasized aspects of the job (P-J fit), including what the job required (e.g., the job 'meshes with my skill set' - demands-abilities fit) or offered (e.g., 'it's a really complex job and I'm always challenged' - needs-supplies fit). Still others emphasized their fit with other individuals (e.g., P-S or P-G fit; 'it's obviously all about the relationships and if I click with the people I work with'). We found extensive evidence that their views of fit were consistent with established conceptualizations in the literature.

In terms of how they constructed their response to "do you fit?", we were surprised to find almost every participant made explicit temporal comparisons to past and/or future fit. Chet's quote in the introduction, alluding to his future fit being worse than current fit, was a foreshadowing of this finding. As another example, Trixie spontaneously introduced her past fit to characterize her current fit:

I do [fit]. It took a while for me to get used to it though, because I came from a very structured environment...And when I came to [this company] I was like, what do you mean - here's A, here's Z, you figure out how to get there - I wasn't used to having permission to do that.

In other words, participants seemed to view their current fit not in an absolute sense, but only in relation to fit at other points in time, demonstrating the pervasive role that psychological time travel plays even when asked about current fit at one moment in time. These temporal comparisons may be one mechanism by which individuals make sense of their current fit, that is, 
by contrasting it with retrospected and anticipated fit. To explore this idea further, we explicitly asked participants to travel across psychological time to consider their past fit and future fit.

Fit in psychological time - retrospection and anticipation

In examining participants' responses regarding retrospections of past fit, we noted that they frequently bracketed and labeled periods of past fit experience (coded as chapters) to create meaningful time intervals for things that had already occurred (Weick, Sutcliffe, and Obstfeld, 2005). These chapters seemed to capture distinct periods of fit or misfit (e.g., 'first five years' or 'last ten years'), the accomplishment of a particular goal, or the development of a set of skills (e.g., 'I'm only three months in, it's a honeymoon' or 'at first it was exploration...now it's how do I make a difference'). Retrospections about past fit were also frequently characterized by two prominent first-order codes: vivid (i.e., detailed description, specific dates) and emotional (i.e., significant low points, difficult to recount), suggesting that only a subset of all past fit experiences may be drawn upon when retrospecting. The passage below exemplifies both of these codes, in which Fred described misfit with a former manager's 'style' (i.e., P-S fit) and a poorly timed request to relocate:

[My manager's] style was not what I wanted, he micromanaged me from afar. And he wanted me to move. I was in New Jersey, stuck there for nine days because of 9/11. I was there for a two day business trip; it became a nine day business trip. And he tried to get me, on September 13, 2001, to relocate to New Jersey! The twin towers were still burning!... It was chaos.

In addition to retrospections about past fit being vivid and emotional, they were also conveyed via richly detailed stories that had a distinct plot (i.e., a purpose for the story) and a clear beginning, middle, and end (Gabriel, 2000). These stories felt significant or defining, in that they seemed to have been well-told, and had somehow challenged their sense of self (cf. McLean et al., 2007). For example, the quote below provides a snippet of a longer, detailed story Tyler told us about the contrast between good fit with his organization in the past and significant misfit that led him to consider a new job:

I remember sitting at my desk. I had a nice little office that looked over the pool. I've got the full application printed out. I'm sitting there and the submit button's looking at me. I'll always remember that, like how it changed...It went from the best and the brightest and, Wow. It went from standing in my lanai in Hawaii - listening to Buffet - thinking, Wow, I am so blessed, and I 
am so lucky... to just a real deflation very rapidly...I'm sitting there thinking, should I give up the whole seniority, give up everything I've had?

In contrast and perhaps not surprisingly, anticipations about future fit were less detailed and more tentative compared to current or retrospected fit. This is consistent with Trope and Liberman's (2003) view that more distant future events are construed more abstractly than events closer to the present. Although a few individuals portrayed the future as certain in the very near term, the majority expressed uncertainty due to ambiguities in their work environment or in their personal situations. Interestingly, we also observed that some people created stories of future fit that introduced a possible alternative future such as a career change ('go manage a Subway'). These stories were particularly common for individuals who were currently experiencing significant misfit. For example, Sara's current fit with her supervisor was very poor, and when asked about her future fit, she first responded:

What I'd like to do is open up a quilt shop. Now, financially, I don't see that happening unless the government gets out of its hole and awards grants to women or whatever [but] that's what I'd like to do. [Would you quit?] Probably. Yeah. [starts crying] It hurts to say I don't want to be here.

However, she then went on to happily describe where the store would be, what equipment she would buy, and how the store would operate. These alternative stories of future fit seemed to offer a salve to the pain of current misfit.

Related, while contemplating anticipated future fit, some individuals seemed to be processing unresolved issues with current fit, such as whether they could continue to tolerate misfit in their current role or make a significant change. Earlier we noted that when asked about current fit, individuals drew temporal comparisons with the past and future. Interestingly, participants did not make any temporal comparisons when retrospecting about the past, but when asked about future fit, individuals frequently drew additional temporal comparisons with current or past fit. In fact, almost twice as many temporal comparisons were made when contemplating future fit than current fit. The ambiguity of future fit seemed to necessitate additional temporal comparisons to determine its nature. For example, when asked about her future fit, Bailey returned to the present moment to grapple with the likely next role of CEO: 
I don't know. When I think about where I'm at, right now I want to get back to what I want to do, and I want to do this business plan, and I want to launch this next business, and I want that to consume me for however long that takes...Sometimes I like the idea of being a CEO, and then sometimes I'm like, [my CEO] is responsible for everything. From a career...just pure professional [perspective] I like that. I'd entertain the idea. But I'm also a mother and a wife. I look at it from that perspective, too.

Similarly, Briana highlighted that she was thinking about her fit in the future quite often because of current misfit and her anticipation of the next role:

And I've been kind of thinking about [my fit in the future]...because I'm so focused on everything right now... and then having to drive to work the other day, and then having to cross the picket line again. You know? I was like, phew. And I was just thinking, can I do this for the next 26 years? [Is that how long it is until you retire?] Yes. Don't think I haven't calculated that...then I think, can I do this?...I know that the first line manager position that I'm looking to get within the next five years... is going to be challenging. And I think, how am I going to be able to make it through that? How long can I stay in that position and be okay with it?

Characteristic trajectories of temporal comparisons Because temporal comparisons were so prevalent in individuals' thoughts about current and future fit, we looked for patterns in how temporal comparisons between past, present and future were linked and combined. We identified four distinct trajectories in participants' responses that we describe below, supplemented by graphical depictions and illustrative quotes in Table 2.

\section{--- Insert Table 2 about here ---}

The first two trajectories are inversely related with respect to the slope from past to current fit (i.e., bad to good versus good to bad, respectively). We labeled the first trajectory pattern as a temporary setback, meaning these individuals' current fit was not as positive as it had been in the past, but was expected to improve in the future. For many of the individuals describing this pattern, current misfit was related to a recent job change or training to take a different job. For example, Julianne explains how the fit at her new job was still evolving:

I think I do fit but it is evolving at the same time. I'm not convinced that either my manager or I know what this role will eventually be... I don't think I'm not a good fit. I think that I have a learning curve.

The newbies in our theoretical sample all described a truncated version of this trajectory. They did not make temporal comparisons with their past fit, perhaps because they did not have much experience upon which to draw. Instead, they reported some amount of current misfit, with expectations that fit would improve in the future as they gained skills and experience. 
The second trajectory described individuals who were riding the wave, in which current fit was seen as an improvement from past fit, and the future was either not mentioned (denoted as a question mark in Table 2) or was anticipated to remain positive in the future. As Bailey's quote in Table 2 illustrates, these individuals acknowledged positive changes in comparison to fit in the past. The seniors in our sample also followed this trajectory. Although they mentioned retirement more than those in our primary sample, they seemed to be content to focus on the present moment and the fit they were enjoying. A similar pattern was found among the job hoppers, although for different reasons. Specifically, even though job hoppers focused on the present moment and riding the wave while it lasted, they were more practical and realistic in their expectations that it would eventually come to an end, at which point they would simply move on (e.g., Carla commented, 'I still feel like I'm a good fit for the organization. I think it'll be interesting in 14 months [when we do the merger] if I still feel that way.').

The final two trajectories depicted in Table 2 share a pattern where future fit is anticipated to be worse than current and/or past fit. We labelled the first of these patterns as anticipated decline. These individuals recounted good past fit and good current fit. However, they anticipated that future fit would not be as positive, such as when a forthcoming organizational change was forecast to reduce their fit. In the current moment, however, these individuals remained open to the possibility that something could change to improve their fit.

Individuals in the final trajectory characterized their fit in terms of a downward slide, in which current fit was worse than past fit, and fit in the future was predicted to continue the decline, such as when a new boss had eroded previously good fit and they anticipated that the situation was only getting worse. These individuals clearly recognized their decreasing fit, and expressed thoughts of leaving their organizations. Further, everyone in this trajectory reported feeling 'trapped', in that they knew fit was worsening but something prevented them from moving on (a point to which we will return in a later section).

Thus far, we have explored responses to interview questions focused on current fit, the retrospected past, and the anticipated future (i.e., traveling across psychological time within one 
moment in clock time). We found that chapters and detailed and vivid stories were used to organize and convey past fit experiences. In contrast, temporal comparisons and the trajectories they created were employed as a mechanism for understanding current and future fit. Finally, individuals experiencing significant misfit constructed alternative stories of better future fit.

These findings provide the first building block for a psychological and temporal process model of fitting. Figure 1, adapted from Jaques (1982), depicts clock time along the x-axis, and psychological time as the rotated y-axis. Although subsequent sections of our paper will describe additional aspects of the model built from our data, here we begin our focus on the first rectangle at the left of the figure (label 1). Each of these rectangles represents a momentary slice of clock time with forward and backward travel in psychological time. Triggered by events, or even simply being asked “do you fit?”, these slices represent a momentary fit assessment whereby individuals draw temporal comparisons with past and future fit. The resulting fit trajectory helps them to assess current fit. The multiple cards exemplified in Figure 1 highlight that individuals may experience a myriad of momentary fit assessments across clock time.

-- Insert Figure 1 about here --

To further develop the process, we were curious to know when and how these momentary fit assessments were triggered. Consistent with event-based research (Morgeson et al., 2015; Pillemer, 2001), we found that external events were by far the most prevalent trigger for initiating thoughts of fit in our data (a full analysis of triggering events is available upon request). Here we focus on a second mechanism our data revealed.

"Tight shoes" When asked what led participants to think about fit, we were surprised to hear that, for the most part, they did not regularly think about it (e.g., 'You know it's funny, [fit is] not something that I think of every day') unless events introduced misfit (e.g., '[when I] hit something here where I'm frustrated'). In other words, events must be accompanied by a recognition of tight shoes (a memorable term Sean used that became our in vivo code):

I think you don't think about fit if you do fit. If you don't fit or someone doesn't fit then you do think about fit. It's kind of... unless your shoes are too tight, you don't think about your shoes. 
Among our long-tenured participants, it appears that external events that perpetuate current fit received no special attention. Instead, only events that introduce, highlight, or intensify misfit initiate thoughts of fit. In Figure 1, this is represented by the border (or lack thereof) on the momentary fit assessment rectangles (label 2). Whereas the first rectangle has no border (i.e., individuals do not think about fit when it is good), a border on the subsequent cards indicates that some degree of misfit has emerged, which requires sensemaking.

To further explore the process by which misfit developed and grew, we dug deeper into participants' past fit experiences. We identified two process journeys by which misfit accumulates: an accumulation journey and an identity-threat journey. We describe these journeys using evidence from our participants below.

Accumulation journey The accumulation journey (label 3 in Figure 1) involves recognition of misfit (i.e., tight shoes) and sometimes lengthy periods of accumulating and tolerating misfit. In our data, individuals began to pay attention to accumulating misfit through two mechanisms that helped them better understand its significance: pattern recognition and toleration. First, individuals sometimes recognized patterns in their fit, either in the environment or within themselves. In both examples below, pattern recognition occurred while reflecting about fit, and provided useful insights for subsequent coping and action. For example, Rob recognized a continuing pattern of misfit based on leadership changes in his organization (i.e., the E of P-E fit) that he likened to 'train wreck \#3':

I try not to think about [the misfit]...You see the new guys come in and make all the old mistakes, and after you've been through that three times, literally I've been through that three times in the last 10 years alone, and I'm watching it; it's like slow motion train wreck \#3...we've danced this dance before and I'm pretty confident I know how it ends.

Alternatively, while travelling forward and backward in psychological time, some individuals recognized patterns in themselves (i.e., the $\mathrm{P}$ of $\mathrm{P}-\mathrm{E}$ fit) that they tended to repeat over the passage of clock time. For example, after a lengthy discussion of past fit experiences, Maia acknowledged a pattern of needs-supplies fit and misfit she continued to enact over time: 
I do really want to retire, like, in 10 or 15 years, so how hard do I want to work?...but I know my personality. I always get into these jobs where I need to slow down, I just want to take it easy. [Then when] I find one of those jobs, I'm like, I need something to fuel me. So I have a feeling I'm just going to be going pretty strong until the very end.

Second, many individuals acknowledged that they psychologically accumulated and tolerated misfit over extended periods of clock time. One of our participants referred to the accumulation of misfit as 'baggage' building up over time the longer he worked with his colleagues, increasing his overall misfit with his work team. Others referred to accumulation as 'sand in the hour glass'; a progression from 'one of those things that was small in the back of my mind' but becomes more prominent over time; a 'seed that gets planted' and grows: or as something that 'wasn't large enough or significant enough to make me do something earlier.' These quotes demonstrate that thoughts about fit may need to accumulate before becoming actionable as the individual looks for clear evidence of misfit and patterns that may not be tolerable. Our participants also clearly acknowledged that they cognitively chose to tolerate misfit for some period of time. For example, Fred was willing to tolerate values misfit to see if he could adjust to the organization over time:

I kind of knew within a few months, this is not the culture for me but let me give it some time, let me see if I can fit in.

Similarly, Rob tolerated person-job misfit to avoid negatively impacting his team:

The job that I have right now I can do in my sleep. It's not a very challenging position... And my boss has said, Look if you left the team it would cause irreparable damage...I'm like, Hey, that's really nice. But the stark reality is...I've taken what I perceive to be, I think most reasonable people would perceive to be, a pretty good step back in the progression of my career, and that's only going to be acceptable for so long.

Given that the accumulation journey can occur over long periods of clock time, sometimes effective coping activities or a separate misfit-reducing event substantially reduced or resolved current misfit. Although very infrequent in our data, when either of these happened, individuals reported going 'back to happy' in terms of their fit (in Figure 1, we figuratively depict this as psychologically returning to a riding the wave trajectory), where they no longer thought about misfit and the process starts anew. For example, Briana had been tolerating misfit in her job, but upon receiving a promotion (i.e., a misfit-reducing event), she went 'back to 
happy doing my job' and no longer thought about her fit. More typically though, the accumulation journey ended by reaching a threshold, an outcome shared with the next journey.

Identity-threat journey The identity-threat journey (label 4 in Figure 1) involves one or more intense identity-threatening events leading to realizations of 'who I am' that made the misfit intolerable. In this journey, thoughts of fit were initiated suddenly when one or more discrepant events led individuals to question whether their organization's values jeopardized their own beliefs and values (depicted as a lightning bolt in Figure 1 that breaks through to the identity layer). For example, our opening quote highlighted how a single event of seeing her CEO's open letter triggered Elizabeth to realize that her organization's values were at odds with her personally-held beliefs, causing her to seriously question her fit. Similarly, in our data Jeff described one single and significant identity-threatening event ('boom') that necessitated an immediate consideration of whether his values fit with those of the former and incoming leaders in his organization:

We had three officers... Next thing you know, there's an ethical concern. Taxes, evasion, jail...boom - there goes your executive management. You know? Yeah... Switch, and now we had a new management all within a matter of weeks...

Upon encountering a 'boom' event, individuals then engaged in a deeper consideration of their identity and their broader fit with the organization. When this consideration led to a clear recognition that the values mismatch threatened their sense of self, they quickly reached a threshold for taking action to resolve the painful journey.

Reaching thresholds Both the accumulation and identity-threat journeys ultimately were resolved by reaching a threshold where misfit had become intolerable and decisive action was needed. In some situations, an extended accumulation journey culminated in an identity-threat journey (represented in Figure 1 as the dotted line from an accumulation journey to an identitythreat journey). For example, Chet had recognized that misfit had accumulated over a long period of clock time, but the passage below highlights the culmination of several fit-impacting events (e.g., a poor performance review, an ill partner, and an uncertain future) that, in one 
significant afternoon at a poignant moment in psychological time, challenged his identity and moved him to respond.

We'd had a lot of problems [at work]. I'm in a meeting with my boss at the time...we're talking about why I should still be working there. Yeah, that was a very difficult discussion. Later that day, I actually had to go home. My wife was - she has this disease that causes paralysis, and I had to go home to help her. And on the way home, that was just like, wow. I don't want to come back here right now and my wife is in a very uncertain - she's beautiful now, she's doing great, but at the time, it was a low, absolute low point in my life. All of these things converged on a single day in a single couple of hours. I think that that was a turning point where - okay, now I'm not sure that I fit in and these are conversations I should have with my boss.

Similarly, Denise describes how the accumulation of long hours, no down time, and pressure from her children reached a climax in one sudden and clarifying moment ('uh-uh'), in which it became clear that her work environment was challenging her identity as a mother:

[The turning point] was just - it was really that summer...I was at [work] all the time and my girls were - they were about...second grade and fourth grade, and so they kept saying, Well, are we going to go on vacation? When are we going to go and what are we going to do? And I just felt so overwhelmed by work and the fact that I really can't... I'm gone during the week. I'm gone during the weekends...this isn't getting better...it's getting more taxing....all of a sudden it was just like, Uh-uh.

As mentioned earlier, accumulation journeys were generally longer, with misfit experiences adding up over time or becoming increasingly less tolerable. Although observers might see the final action as sudden and unexpected, in reality the misfit likely had been accumulating for some time. Alternatively, or following an accumulation journey, identity-threat journeys were more rapid and quickly led to a definitive threshold, such as Maia saying, 'Okay, I'm done. I'm done' (label 5 in Figure 1). These 'I'm done' moments became the impetus for action and triggered a full assessment within psychological time in which the whole story was clear. Regardless of the journey to a threshold, upon reaching one, individuals could tolerate the situation no longer, leading to swift and decisive action.

As alluded to earlier, a few unfortunate individuals in our sample (all in a downward slide trajectory) reported being 'trapped' or 'stuck' because they were constrained by a system (e.g., seniority or time-sensitive investments) that kept them in a holding pattern of poor fit. For example, Tyler recognized that, although he loved his profession, he was a misfit for his 
company. Due to a seniority system that would force him to start over if he changed employers, he made a decision to stay and then rationalized his reasons for doing so.

I kind of reached the low of the low, but I decided deep inside that I wanted to be [in this profession]. That's the way I wanted to provide for my kids. So for me that was sort of a relief...this is what I'm going to do... [But then] it's kind of like you make that decision and then you're trapped.

Interestingly, however, instead of helping him cope, his decision increased how frequently he thought about his misfit and simultaneously precluded him from taking action to resolve it. We acknowledge these trapped individuals in Figure 1 as stuck behind the wall of the threshold, barring them from taking action.

In sum, we have identified several sensemaking mechanisms, and two process journeys individuals followed, which played out over time. We were initially surprised by the identitythreat journey because prior P-E fit research had not explicitly examined identity-related considerations of fit. Therefore, we searched for other identity-related patterns in our findings, informed by the connection between the sensemaking perspective and identity. We observed that some individuals recognized when a particular fit experience was perfectly suited to them (e.g., 'This is me. This is who I am.'). Others described how and why formative life events influenced their personal sensemaking about fit, such as the following passage from the "trapped" pilot Tyler, who explained why he would not leave his profession:

I'm the son of Teamsters truck driver, one job. My mom had one job, a nurse at the VA hospital her whole life - I think I'm very conservative financially and I think the thought of changing jobs, rolling the dice, giving up and going and finding something else scares me to death in a lot of ways.

These observations, combined with Braden's statement below, sparked our interest in further examining our data for a more stable identity-related "underlying theme" in the fit experiences our participants had recounted about their past fit.

My [fit] story is like a series of vignettes - maybe a novella. Like Voltaire's Candide, 30 chapters that are different but there is an underlying progression. I am the constant - I am still the same person at the core... The scenery changes, environments change, even I change somewhat, but I am the underlying theme.

We therefore returned to the data to consider other identity-related patterns in our findings. 
Fitting across recounted clock time - fit themes

As we widened our search for more stable patterns, we implicitly moved our focus from psychological time to clock time. To be precise, we shifted our focus from the psychological construction we observed during the interview to the content and recounting of the overall fit experiences that had occurred with the passage of clock time. Two prevalent codes in our data captured our attention as they seemed to reflect implicit beliefs about the person that held across multiple fit experiences. These codes anchored opposite ends of a continuum from being selffocused (e.g., quid pro quo) to other-focused (e.g., caretakers) in terms of their preferred fit. We examined the data and first-order codes, using these in vivo codes as our starting point. After several iterations between data, codes, and theory, we identified four prototypical patterns of fit preferences that were employed across a variety of experiences over clock time, reflecting the individual's sense of self and influencing the actions they took. Table 3 provides a summary of the four fit themes.

Transactional fit theme The most self-focused theme we labeled transactional fit, which built upon the quid pro quo first order code. These individuals' transcripts revealed patterns of self-interest and a transactional needs-supplies view of their fit, emphasizing that they experienced good fit only to the extent that they received what they wanted in terms of pay, status, rewards, or recognition. One of the most prevalent codes was the need for career advancement opportunities, such as Roberto saying: I would like to...continue moving up more in the organization.' Individuals exhibiting this theme were primarily concerned with what they were getting from their employment, as illustrated in Table 3 and Heidi's comment below.

So these conversations that we've had - I mean this is a two-sided deal here. I want [organization] to get what they want, but I also need to get what I want.

It may be counterintuitive that our long-term tenure sample would include anyone in the transactional fit theme, because it would seem individuals whose self-image highlights the notion of quid pro quo would be ready to move elsewhere if their needs were not met. However, for each individual, their needs continued to be met, which may have been an artifact of working for 
large organizations where they had more opportunities for internal job changes and upward movement in the organization. Perhaps not surprisingly, all three job hoppers in our sample also exhibited this theme. They tended to have a rather pragmatic view of staying while their talents were of value, then moving on to new opportunities.

--- Insert Table 3 about here ---

Instrumental fit theme The second theme, instrumental fit, emphasizes achieving personal goals either through the work or through people who will help to meet those goals. In contrast to the purely self-focused transactional theme, actions and priorities by individuals exhibiting this theme repeatedly emphasized situations with skill-based growth, learning, and challenge (e.g., 'It was a good fit because there's an element of learning...something new every day.') and being a content expert (e.g., 'I knew everything that they needed me to do. I didn't need any help, I didn't need any training... so it was just a really great fit.'). Alternatively, some participants highlighted the importance of building or leveraging their interpersonal networks, frequently mentioning fit with respected individuals (i.e., P-S fit). In these instances, interpersonal connections were instrumental in fulfilling their goal of getting ahead. For example, Fred repeatedly relied on personal contacts:

I got my job at [current company]...partially because of my relationship with a guy that I worked with 11 years ago at [previous company]. So there's a relationship link there. I think that my progression within [current company] has been because - and I'm often complimented on this that I do well with relationships.

Affiliative fit theme Those exhibiting the third theme of affiliative fit, continually emphasized the importance of being a contributing member of or feeling a sense of affiliation with the work unit, organization or profession. In comparison to the previous themes, this theme shifts from self-focused to other-focused, emphasizing one's need for social attachment. Some individuals expressed good fit when they shared values and were feeling valued and appreciated by the organization. For example, one of Chet's high points in terms of fit was having his coworkers vote him as the most impactful person in the organization. Other participants mentioned the importance of belonging and feeling cared for. Individuals in this theme also 
frequently referred to helping others at work. Some participants, such as Lynita, went further, referring to their groups or organizations as family or home (i.e., 'I have a home here...I feel appreciated').

Custodial fit theme The final theme for custodial fit emphasized the collective even more prominently, characterized by in vivo codes such as caretaker, janitor, and bridesmaid. In this theme, individuals described themselves as taking care of their coworkers, supervisors, and organizations. They felt that their value to the organization was based on handling issues that others did not want to do and acknowledged that they were 'pleasers' who contributed selflessly. In our sample, the custodials were all women. Also worth noting and perhaps not surprising, custodials as a group had the longest tenure and had worked in the fewest organizations compared to those in other fit themes. Their selfless tendencies put these individuals at the other end of our self-collective continuum. Perhaps because of this, they acknowledged that their people-pleasing ways sometimes came at a cost, as Megan's quote highlights:

My [career] coach told me that I've been loyal to my own detriment. I'm extremely loyal. I haven't really focused on what's best for me. It's like every year I find myself with one new ailment from working there, stress-related, physical type ailment. So I think about it a lot but I don't do anything about it.

In considering the four fit themes as a set, the first two seem to emphasize a preference for P-J fit (i.e., needs-supplies or demands-abilities fit), whereas the latter two emphasize P-O fit (and to a lesser extent P-S and P-G fit), including social- and values-driven experiences. However, all four themes seem to reflect stable identity-related preferences that hold across a variety of work experiences over the recounting of clock time, which is portrayed as the foundation of Figure 1. That is, as they described their thoughts and actions over multiple fit experiences over clock time, the fit themes represented how individuals fundamentally view themselves at the intersection of fit and identity.

Fitting across actual clock time - stability versus change

To further understand how our findings from the first interview played out across the actual passage of time (i.e., following participants over clock time, not just their recounting of it), 
we obtained status updates from all of our participants, and interviewed two-thirds of our full sample 12 to 18 months after the initial interview. In terms of process, the follow-up interviews provided evidence that many of the mechanisms depicted in Figure 1 were evident a year later. Specifically, temporal comparisons remained prevalent, as individuals again spontaneously compared their current fit to past fit or anticipated future fit. In addition, stories of past fit from the first interview were repeated (verbatim, at times), reinforcing that they were well-told and influential in individuals' sensemaking about fit. Finally, new events also had been incorporated into participants' recounting of fit experiences, whether the materialization of a previously forecasted promotion or unanticipated changes that were now salient. We also explored whether fit themes and trajectories persisted or changed with the passage of clock time.

Stable themes The fit themes remained stable without exception, providing some assurance that they are tapping a more enduring and identity-related characteristic. Moreover, an individual's fit theme helped to explain how and why changes (if any) had occurred. For example, Bailey, whom we classified as instrumental from preferences evident in the first interview, left her job because she no longer felt challenged. Similarly, Megan, whom we characterized as a custodial based on the first interview, only changed companies after repeated urging from her doctor and executive coach, and described the quitting process as a 'divorce.' Alternatively, Heidi, a long-tenured transactional, described the circumstances that continued to keep her in her current organization:

I think the most important thing that I've seen through my last 15 years is that [organization] has stretched to fit me and has found opportunities for me to fit. So if I'm still at [organization] in five years, that is going to be the constant.

In the year between our initial interview and follow-up status, affiliatives as a group experienced no significant changes in their work environment, while all but one instrumental experienced a job or organization change. Finally, of the three trapped participants, Rob (a transactional) changed organizations quite quickly after the interview, while Chet and Tyler (both affiliatives) were, respectively, pushed out after lengthy consideration, or remained 
trapped. These preliminary observations suggest that fit themes may be useful in predicting behavior across clock time.

Stable and shifting trajectories Among those we interviewed a second time, more than a third described the same trajectory pattern they had characterized in the first interview. Notably, these were also the individuals who had not reported any significant fit-related changes in their work situation in that time frame. For example, Tyler described his current fit using temporal comparisons that were consistent with his earlier characterization (downward slide and 'trapped'), and Toby continued riding the wave.

The remaining individuals had experienced fit-impacting changes, and these were reflected in new temporal comparisons and a concomitant change in their trajectory. For example, Sara (previously anticipated decline) had been coping with poor supervisor fit when we first interviewed her and had crafted a detailed alternative future fit story (retiring early and opening a quilt shop). Yet in the follow-up interview, after a new supervisor had arrived, she was more ambivalent about those alternative plans for reestablishing fit:

It's not that I've shelved it, it's just I might be being a little bit more cautious than I was thinking [in the first interview]... There's all sorts of things to think about. Do you want to do it all? I think it would be fun to have a business... but then you tie yourself down in another way.

Instead, the arrival of a new supervisor had resolved her misfit. In response to these fit-related changes, her pattern of temporal comparisons at the follow-up interview had shifted from anticipated decline to riding the wave. She stated that once she knew the next supervisor was coming, she was 'pretty well a happy camper,' and was now delaying her retirement to gain even more years of service.

In contrast, when we first interviewed Todd, he was riding the wave and had characterized his current job as highly aligned with his career goals. However, in the subsequent interview, he had taken a new job within the corporate headquarters of his organization and had since become pessimistic about his fit in the future. The temporal comparisons he made when asked about his current fit were now consistent with the anticipated decline trajectory. He even 
admitted that after 15 years of tenure, he had begun to think about leaving the company (which he did soon after our follow-up interview).

These trajectory findings across clock time further contribute to our understanding of how individuals make sense of fit. First, the recounting of previous fit stories and the incorporation of new events reinforce the driving role that events play in introducing, increasing, and making sense of misfit. Second, Sara's experience suggests that alternate stories of future fit that individuals create may simply be a longitudinal form of defense (French, et al. 1974). They are either discarded once current misfit is resolved, or they are elaborated, embellished, and eventually enacted. Finally, these findings suggest that trajectories shift over time in response to fit-impacting events. For some, in the absence of significant events the trajectory endures, but for others, it evolves to reflect changes.

Unexpected turnover Across our full set of participants, we also tracked whether individuals had experienced any changes with their work environment in terms of a new job or supervisor within their organization, or a new organization altogether (i.e., turnover). Table 1 provides status updates for each of our participants. Perhaps not surprisingly, within the theoretical sample, all of the job hoppers but none of the seniors had changed organizations. What was surprising, though, was that $30 \%$ of the long-tenured purposive sample had changed organizations within 18 months of our initial interview. This finding was potentially concerning given that these individuals had an average of over 12 years tenure prior to quitting. One possible explanation is that in talking during the interview (which some described as 'therapeutic'), and hearing their constructed stories of fit, they recognized accumulated patterns of misfit or inconsistencies between the person (the P) and the current environment (the E), which led them to a threshold and, ultimately, turnover.

An alternative possibility is that the individuals who left may have been on a trajectory of anticipated decline or downward slide, and this trajectory simply unfolded over time. In fact, five of the seven people in our purposive sample who left had described one of these two trajectories. Only three other individuals in the purposive sample who did not leave had reported one of these 
trajectories. One was trapped, and the other two had experienced 'back to happy' moments in response to job or supervisor changes. While only suggestive, these findings indicate that these trajectories may be useful in understanding when misfit will lead to turnover.

\section{Discussion}

We sought to understand how individuals make sense of fit as they experience personal and organizational change. We had witnessed reversals in how colleagues characterized their fit from one year to the next, assumedly to achieve consistency with evolving roles or changing circumstances, and we were curious to understand when and how their characterizations changed. We utilized a qualitative lens, interviewed employees with long-term tenure to collect their fit-related stories, and traveled with them across both psychological time and clock time. What we found breaks from traditional thinking about fit as predicting outcomes in the moment, to fitting as both a journey and a retrospective and prospective process of sensemaking.

\section{Contributions and future research}

Overall, our study provides insights into the process by which long-tenured individuals make sense of fit over time, making three contributions to the fit literature. First, the prevalence of temporal comparisons demonstrates that we cannot understand how individuals interpret current fit without considering what they recollect and forecast. This empirical finding supports recent theorizing about fit narratives (Shipp and Jansen, 2011), but also extends it by identifying that temporal comparisons combine to form prototypical trajectories. The trajectories we discovered, representing momentary, holistic snapshots constructed from retrospected, current, and anticipated fit, help to explain how two people can experience the same objective fit in the moment (e.g., poor fit with a new supervisor), yet describe and respond to their current fit in different ways. In other words, each person comes to a job/organization with a different set of past fit experiences and expectations of future fit, and the resulting difference in trajectories influences their response to misfit in the current moment. As our model shows, fit trajectories are constructed to make sense of fit-related events. As such, they are momentary and susceptible to change over time as events occur in the work environment. Further, evidence from our 
longitudinal findings suggests that trajectories in which future fit is anticipated to decline (or continue to slide downward) seem to predict turnover quite well, signifying that trajectories also provide a window into who is likely to stay or leave when confronting misfit. Combined, these findings highlight that cross-sectional measures of current fit may be deficient. Capturing fit only at a moment in time overlooks the temporal context of retrospected and anticipated fit, which are key mechanisms by which individuals evaluate current fit. Based on these findings, future research should consider alternative approaches for assessing fit, whether qualitatively through interviews, or quantitatively through new measures of retrospected and anticipated fit. Alternatively, researchers can capture and leverage graphical trajectories (cf. Meyer et al. 2013; Nelson and Jansen, 2009; Roe and Inceoglu, 2016) to explore how various slopes and shifts in perceptions of fit predict current and future behavior and turnover.

Our second contribution is a greater understanding of the process by which individuals think about and respond to (mis)fit over time, supporting and extending findings by Follmer et al. (2018). We identified two common journeys: accumulation and identity-threat. The first involves misfit-inducing events, temporal comparisons, and a (sometimes extended) period of pattern recognition/accumulation/toleration, which led to either renewed fit ('back to happy') or reaching a threshold ('I'm done'). The accumulation journey extends the range of tolerance idea posited by previous fit researchers (cf. Caplan, 1983; Kulka, 1979). Whereas the original conceptualization focuses on reaching an intolerable degree of misfit (i.e., the level of misfit) at a single point in time, our data suggests that there is also a temporal range of tolerance (i.e., the duration of misfit). That is, beyond any one event creating intolerable levels of misfit, individuals will continue to tolerate and accumulate instances of misfit until they exceed their temporal range of tolerance. In contrast, the second journey involves one or more identitythreatening events, realizations of personal and organizational values misalignment, and a sudden 'I'm done' threshold. This identity-threat journey surprised us because to date, fit research has largely overlooked the role identity plays in assessing person-environment fit. Asking 'who am I?’ seemed to reflect an “ongoing accomplishment” (Langley et al., 2012: 138) 
of simultaneously adapting to the environment while trying to maintain a sense of self. The implication is that identity-related sensemaking about fit is inseparably linked with $\mathrm{P}-\mathrm{O}$ values misfit, adding to research examining how (in)congruent values relate to various outcomes (Edwards and Cable, 2009) including workplace change (Klag et al., 2015). One clear research implication from both journeys is that we should not focus on current fit and current workrelated contextual factors alone. Past fit experience and lengthy periods of accumulation and toleration are important considerations when investigating P-E fit. These journeys also highlight that the work environment is not the only factor at play in making sense of fit. Our findings suggest that personally-held values and identity play a significant role in how fit evolves over time, emphasizing the importance of the understudied "P" portion of the fit equation.

Further building on the link between fit and identity, our third contribution is a recognition that individuals exhibit one of four identity-related themes (i.e., transactional, instrumental, affiliative, and custodial), highlighting the types of fit experiences they are repeatedly drawn to over time. In essence, fit themes reflect what one values, wants, or can do in regard to fit, which is carried from one fit experience to the next. In the same way that sensemaking is enacted, produced, and reinforced, fit themes may become "more resilient in the face of criticism" (Weick et al., 2005, p. 415) and more enduring over time, making them an important consideration for future fit research. At a minimum, additional research is needed that establishes the validity of the fit themes we observed across a wider array of individuals. In the longer term, research that better integrates fit and identity is warranted. In fact, recent identity research acknowledges the multiple understandings that individuals hold about themselves, including past, present, and alternative selves (Peetz and Wilson, 2008; Obodaru, 2012), and how former role-based identities may linger following a role change (Wittman, in press). Our findings suggest that both fit and identity are relevant considerations as individuals navigate changing roles and work environments over time.

Beyond the aforementioned directions for future research on fit and identity, our findings also provide opportunities for future research at the nexus of sensemaking and fit. The 
sensemaking perspective holds that individuals make sense both retrospectively and prospectively, yet typically has emphasized the retrospective aspects (Maitlis and Christianson, 2014). Our findings, such as future temporal comparisons, trajectories that incorporate (and are defined by) anticipated future, and alternative stories of future fit, underscore that prospective sensemaking is an equally if not more important mechanism. Combining these findings with other recent research (Gephart et al. 2010; Stigliani and Ravasi, 2012), highlights the need for research that explicitly considers how and when individuals use prospective sensemaking in addition to, or even in lieu of, retrospective sensemaking. Given the ambiguity and malleability of future perceptions, the former may be more helpful than the latter in crafting the story one needs to endure a difficult situation.

Earlier we commented on one of our personal motivations for conducting this research namely, to understand how our colleagues' characterizations of their fit changed significantly from one year to the next. Many of the fit stories in our data included mentions of coaches, managers, and leaders, suggesting that others may play an important role in fit-related sensemaking. Thus, further theoretical integration between fit research and sensemaking constructs such as sensegiving (Gioia and Chittipeddi, 1991; Maitlis and Lawrence, 2007) and sensebreaking (Pratt, 2000) may be fruitful. Questions to consider include the role other actors play in giving sense about fit, whether positively shaping or even violating the focal actor's sensemaking about fit. Although our study leaves such questions for future research, our findings suggest that if left to their own interpretations, one simple question like "do you fit" can unintentionally trigger an eventual departure when either the accumulation journey or identity journey is activated. As a result, collective sensemaking about fit may be an important theoretical mechanism to explain retention under conditions of poor fit, or alternatively, collective turnover (Bartunek et al., 2013).

\section{Limitations}

Despite the theoretical and process contributions of our paper, we acknowledge several limitations of our study. First, it should be noted that our qualitative inquiry focused primarily on 
individuals with long-term tenure. Studying different types of employees may provide additional findings beyond those reported here. At the same time, researchers often overlook long-term employees in favor of individuals experiencing fit in the early stages of tenure (i.e., job choice, organizational entry, and socialization; Jansen and Kristof-Brown, 2006), so this population clearly offered many interesting insights about the process of making sense of fit over time. For example, the "tight shoes" finding leading to the accumulation journey was particularly relevant to our long-tenured sample, but was not evident in Follmer et al.'s (2018) qualitative study involving shorter-tenured individuals, who, instead, thought about misfit frequently and quickly questioned leaving. Although our theoretical sample provides some support that our findings may hold beyond long-tenured individuals, future research should validate the sensemaking mechanisms we identified across varying levels of tenure and experience.

A second limitation is that although we identified four prototypical trajectories of fit, there may be additional trajectories beyond these four. For example, individuals could report consistently increasing fit from past to present to future (e.g., a rags-to-riches story; Booker, 2004), uncovering additional nuances in temporal sensemaking about fit. Regardless of whether additional fit trajectories emerge in future studies, it is worth noting that the psychological trajectories we observed were better indicators of behavior than current fit alone.

\section{Practical implications}

There are several practical implications from our findings. First, our participants found that talking about their evolving fit, impactful stories, and vulnerabilities was beneficial and therapeutic, but also quite rare in their experience. The interview seemed to move people from privately-held thoughts about their fit to, once publicly verbalized, a stake in the ground that informed subsequent action. Following Weick et al.'s (2005, p. 416) notion that "when you hear yourself talk, you see more clearly what matters and what you had hoped to say," asking people to share their stories of fit should be a useful activity for personal and professional development. More broadly, managers can also benefit from understanding employees' fit in terms of where one has been and where one is going. By adjusting a managerial mindset from "fit as 
contemporaneous" to "fit as an evolving journey," we can engage in more useful dialog with our employees.

Second, as very few people experience perfect fit, it may be worthwhile for managers to highlight improvements in fit from the past or positive aspects of current fit. Given that the future fit trajectory was influential in terms of turnover, managers may want to engage in sensegiving activities focusing on future fit. For example, when an employee is fast-tracked for higher-level positions, their future fit is not only positive but highly salient (e.g., "you're being groomed for great things"), which may contribute to positive temporal comparisons and longterm tenure. Thus, managers may want to help employees create temporal comparisons that reflect one's fit story in the most positive light.

Finally, if managers can identify the underlying theme of their employee's fit experiences, it would allow them to tailor job offers, new opportunities, and possible solutions for reducing or resolving misfit. In keeping with the notion that managing employees is more like playing chess than checkers (Buckingham, 2005), knowledge of the kind of fit experiences that matter to employees can help managers customize their coaching, mentoring and incentives.

\section{Conclusion}

Some scholars have argued that the field of fit has come to a potential impasse in terms of theory and methodology (Harrison, 2007), such that interesting research questions regarding fit may have reached a dead end. In contrast, we believe fit research is at an important juncture regarding the relevance, salience, and meaning of fit at work. Our qualitative and temporal analysis provided substantial insights into how individuals make sense of fit in the moment and over time, which provided several avenues for future research. Combined, these insights shed light on a rich, temporal process of fitting over time, suggest several opportunities to more deeply integrate fit with other theoretical perspectives, and ensure that fit research will remain alive and well for quite some time. 


\section{References}

Bartunek J, Huang Z and Walsh I (2008) The development of a process model of collective turnover. Human Relations 61(1): 5-38.

Bentein K, Vandenberghe C, Vandenberg R and Stinglhamber F (2005) The role of change in the relationship between commitment and turnover: A latent growth modeling approach. Journal of Applied Psychology 90(3): 468-82.

Booker C (2004) The Seven Basic Plots: Why We Tell Stories. London: Continuum.

Boon C and Biron M (2016) Temporal issues in person-organization fit, person-job fit and turnover: The role of leader-member exchange. Human Relations 69(12): 2177-2200.

Buckingham M (2005) What great managers do. Harvard Business Review March.

Bureau of Labor Statistics (2012) Employee Tenure in 2012. Available at:

http://www.bls.gov/news.release/pdf/tenure.pdf.

Cable D and DeRue D (2002) The convergent and discriminant validity of subjective fit perceptions. Journal of Applied Psychology 87: 875-84.

Caplan R (1983) Person-environment fit: Past, present and future. In Cooper CL (ed.), Stress Research. Chichester, UK: John Wiley \& Sons, 35-78.

Castrogiovanni G (2002) Organization task environments: Have they changed fundamentally over time? Journal of Management 28(2): 129-50.

Charmaz K (2000) Constructivist and objectivist grounded theory. In Denzin N, Lincoln Y (eds) Handbook of Qualitative Research (Vol. 2). Thousand Oaks, CA: Sage, 508-35.

Chuang A, Shen C and Judge T (2016) Development of a multidimensional instrument of person-environment fit: The Perceived Person-Environment Fit Scale (PPEFS). Applied Psychology 65(1): 66-98.

Currie G and Brown A (2003) A narratological approach to understanding processes of organizing in a UK hospital. Human Relations 56(5): 563-86.

Darrow J and Behrend T (2017) Person-environment fit is a formative construct. Journal of Vocational Behavior 103: 117-31. 
Dawis R and Lofquist L (1984) A Psychological Theory of Work Adjustment. Minneapolis: University of Minnesota Press.

Deci E and Ryan R (2000) The what and why of goal pursuits: Human needs and the selfdetermination of behavior. Psychological Inquiry 11(4): 227-68.

Edmondson A and McManus S (2007) Methodological fit in management field research. Academy of Management Review 32(4): 1246-64.

Edwards J (1994) The study of congruence in organizational behavior research. Organizational Behavior and Human Decision Processes 58(1): 51-100.

Edwards J (2002) Alternatives to difference scores: Polynomial regression analysis and response surface methodology. In Drasgow F, Schmitt NW (eds), Advances in Measurement and Data Analysis. San Francisco: Jossey-Bass, 350-400.

Edwards J and Cable D (2009) The value of value congruence. Journal of Applied Psychology 94(3): 654-77.

Edwards J, Cable D, Williamson I, Lambert L and Shipp A (2006) The phenomenology of fit: Linking the person and environment to the subjective experience of person-environment fit. Journal of Applied Psychology 91(4): 802-27.

Follmer E, Talbot D, Kristof-Brown A, Astrove S and Billsberry J (2018) Resolution, relief, and resignation: A qualitative study of responses to misfit at work. Academy of Management Journal.

French J Jr, Rodgers W and Cobb S (1974) Adjustment as person-environment fit. In Coelho G, Hamburg D, Adams J (eds), Coping and Adaptation. New York: Basic Books, 316-33.

Gabriel A, Diefendorff J, Chandler M, Moran C and Greguras G (2014) The dynamic relationships of work affect and job satisfaction with perceptions of fit. Personnel Psychology 67(2): 389-420.

Gabriel Y (2000) Storytelling in Organizations. Oxford: Oxford University Press.

Gephart R, Topal C and Zhang Z (2010) Future-oriented sensemaking: Temporalities and institutional legitimation. In Hernes T, Maitlis S (eds.), Process, Sensemaking and 
Organizing. Oxford UK: Oxford University Press, 275-302.

Gioia D and Chittipeddi K (1991) Sensemaking and sensegiving in strategic change initiation. Strategic Management Journal 12(6): 433-48.

Hall D (1976) Careers in Organizations. Pacific Palisades, CA: Goodyear Publishing.

Harold C, Oh I, Holtz B, Han S and Giacalone R (2016) Fit and frustration as drivers of targeted counterproductive work behaviors. Journal of Applied Psychology 101: 1513-35.

Harrison D (2007) Pitching fits in applied psychological research. In Ostroff C, Judge T (eds), Perspectives on Organizational Fit. Mahwah, NJ: Erlbaum, 389-416.

Ibarra $\mathrm{H}$ and Barbulescu R (2010) Identity as narrative: Prevalence, effectiveness and consequences of narrative identity work in macro work role transitions. Academy of Management Review 35(1): 135-54.

Isabella L (1990) Evolving interpretations as a change unfolds: A study of how managers construe key organizational events. Academy of Management Journal 33(1): 7-41.

Jansen K and Kristof-Brown A (2006) Toward a multidimensional theory of person-environment fit. Journal of Managerial Issues 18(2): 193-212.

Jansen K and Shipp A (2013) A review and agenda for incorporating time in fit research. In Kristof-Brown A, Billsberry J (eds), Organizational Fit: Key Issues and New Directions. Chichester: Wiley, 195-221.

Jaques E (1982) The form of time. Crane Russak \& Co.

Judge T (2007) The future of person-organization fit research: Comments, observations, and a few suggestions. In Ostroff C, Judge T (eds.), Perspectives on Organizational Fit. Mahwah, NJ: Lawrence Erlbaum Associates, 419-45.

Kammeyer-Mueller J (2007) The dynamics of newcomer adjustment: Dispositions, context, interaction, and fit. In Ostroff C, Judge T (eds), Perspectives on Organizational Fit. Mahwah, NJ: Erlbaum, 99-122. 
Klag M, Jansen K and Lee M (2015) Contemplating workplace change: Evolving individual thought processes and emergent story lines. Journal of Applied Behavioral Science 51(1): 36-70.

Kristof A (1996) Person-organization fit: An integrative review of its conceptualizations, measurement, and implications. Personnel Psychology 49(1): 1-49.

Kristof-Brown A and Jansen K (2007) Issues of person-organization fit. In Ostroff C, Judge T (eds), Perspectives on Organizational Fit. Mahwah, NJ: Erlbaum, 123-53.

Kristof-Brown A, Jansen K and Colbert A (2002) A policy-capturing study of the simultaneous effects of fit with jobs, groups, and organizations. Journal of Applied Psychology 87(5): 985-93.

Kristof-Brown A, Zimmerman R and Johnson E (2005) Consequences of individuals' fit at work: A meta-analysis of person-job, person-organization, person-group, and person-supervisor fit. Personnel Psychology 58(2): 281-342.

Kulka R (1979) Interaction as person-environment fit. In Kahle L (ed.), New Directions for Methodology of Behavioral Science. San Francisco: Jossey-Bass, 55-71.

Langley A, Golden-Biddle K, Reay T, Denis J, Hébert Y, Lamothe L and Gervais J (2012) Identity struggles in merging organizations: Renegotiating the sameness-difference dialectic. Journal of Applied Behavioral Science 48(2): 135-67.

Lauver K and Kristof-Brown A (2001) Distinguishing between employees' perceptions of person-job and person-organization fit. Journal of Vocational Behavior 59: 454-70.

Lewin K (1943) Defining the 'field at a given time.' Psychological Review 50(3): 292-310.

Lewin K (1951) Field theory in social science. Westport, CT: Greenwood Press.

Lincoln Y and Guba E (1986) But is it rigorous? Trustworthiness and authenticity in naturalistic evaluation. New Directions for Program Evaluation 30: 73-84.

Locke K, Golden-Biddle K and Feldman M (2008) Perspective-making doubt generative: rethinking the role of doubt in the research process. Organization Science 19: 907-18.

Maitlis S and Lawrence T (2007) Triggers and enablers of sensegiving in organizations. 
Academy of Management Journal 50(1): 57-84.

Maitlis S (2009) Who am I now? Sensemaking and identity in posttraumatic growth. In Morgan Roberts L, Dutton J (eds), Exploring Positive Identities and Organizations: Building a theoretical and research foundation. New York: Psychology Press, 47-76.

Maitlis S and Christianson M (2014) Sensemaking in organizations: Taking stock and moving forward. Academy of Management Annals 8: 57-125.

McAdams D (1988) Power, intimacy, and the life story. New York: Guilford Press.

McAdams D (1993) Personal Myths and the Making of the Self. Guilford Press: New York.

McGrath J and Rotchford N (1983) Time and behavior in organizations. Research in Organizational Behavior 5: 57-101.

McLean K, Pasupathi M and Pals J (2007) Selves creating stories creating selves. Personality and Social Psychology Review 11(3): 262-78.

Meyer R, Höllerer M, Jancsary D and Van Leeuwen T (2013) The visual dimension in organizing, organization, and organization research: Core ideas, current developments, and promising avenues. Academy of Management Annals 7(1): 489-555.

Miles M and Huberman A (1994) Qualitative Data Analysis. London: Sage.

Mishler E (1986) The analysis of interview-narratives. In Sarbin TR (ed.), Narrative Psychology: The Storied Nature of Human Conduct. Westport, CT: Praeger/Greenwood, 233-55.

Morgeson F, Mitchell T and Liu D (2015) Event system theory: An event-oriented approach to the organizational sciences. Academy of Management Review 40(4): 515-37.

Murray H (1938) Explorations in Personality: A Clinical and Experimental Study of Fifty Men of College Age. New York: Oxford University Press.

Nelson R and Jansen K (2009) Mapping and managing momentum in IT projects. MIS Quarterly Executive 8(3): 141-8.

Ng T and Feldman D (2010) Organizational tenure and job performance. Journal of Management 36(5): 1220-50.

Obodaru O (2012) The self not taken: How alternative selves develop and how they influence 
our professional lives. Academy of Management Review 37(1): 34-57.

Patton M (1990) Qualitative evaluation and research methods (2nd ed.). Newbury Park, CA: Sage Publications.

Peetz J and Wilson A (2008) The temporally extended self: The relation of past and future selves to current identity, motivation, and goal pursuit. Social and Personality Psychology Compass 2(6): 2090-106.

Pillemer D (2001) Momentous events and the life story. Review of General Psychology 5: 12334.

Polkinghorne D (1988) Narrative Knowing the Human Sciences. Albany: State University of New York Press.

Pontefract D (2016) A Letter From IBM's CEO To Trump Caused An Employee To Quit. Available at: http://www.forbes.com/sites/danpontefract/2016/12/03/.

Pratt M (2000) The good, the bad, and the ambivalent: Managing identification among Amway distributors. Administrative Science Quarterly, 45(3): 456-93.

Riessman C (1993) Narrative Analysis (Vol. 30). London: Sage Publications.

Roe R and Inceoglu I (2016) Measuring states and traits in motivation and emotion. A new model illustrated for the case of work engagement. In Leong F, Leong D, Cheung F, Geisinger K, Iliescu D (eds), ITC International Handbook of Testing and Assessment. New York: Oxford University Press, 63-88.

Saldana J (2009) The Coding Manual for Qualitative Researchers. Los Angeles, CA: Sage. Sandberg J and Tsoukas H (2015) Making sense of the sensemaking perspective. Journal of Organizational Behavior 36(S1): S6-32.

Schneider B (1987) The people make the place. Personnel Psychology 40(3): 437-53.

Shipp A and Cole M (2015) Time in individual-level organizational studies: What is it, how is it used, and why isn't it exploited more often? Annual Review of Organizational Psychology and Organizational Behavior 2(1): 237-60.

Shipp A and Jansen K (2011) Reinterpreting time in fit theory: Crafting and recrafting narratives 
of fit in medias res. Academy of Management Review 36(1): 76-101.

Stigliani I and Ravasi D (2012) Organizing thoughts and connecting brains: Material practices and the transition from individual to group-level prospective sensemaking. Academy of Management Journal 55: 1232-59.

Sullivan S (1999) The changing nature of careers: A review and research agenda. Journal of Management 25(3): 457-84.

Taylor S and Bogdan R (1984) Introduction to qualitative research methods: The search for meaning. New York: John Wiley.

Trope Y and Liberman N (2003) Temporal construal. Psychological Review 110(3): 403-21.

Watson T (2009) Narrative, life story and manager identity: A case study in autobiographical identity work. Human Relations 62(3): 425-52.

Weick K (1995) Sensemaking in organizations. Thousand Oaks, CA: Sage.

Weick K, Sutcliffe K and Obstfeld D (2005) Organizing and the process of sensemaking. Organization Science 16(4): 409-21.

Wheeler A, Buckley M, Halbesleben J, Brouer R and Ferris, G (2005) "The elusive criterion of fit" revisited: Toward an integrative theory of multidimensional fit. Research in Personnel and Human Resource Management 24: 265-304.

Wittman S (in press) Now bygone or lingering on? Deidentification and identity continuity responses to role change. Academy of Management Review. 
Table 1

Participant Characteristics

\begin{tabular}{|c|c|c|c|c|c|c|}
\hline Pseudonym & Gender & Tenure & Age & Industry - Job Type & $\begin{array}{l}\text { Long-term } \\
\text { Changes }\end{array}$ & $\begin{array}{l}\text { Follow-up } \\
\text { Interview } \\
\end{array}$ \\
\hline \multicolumn{7}{|c|}{ Purposive Sample (9 or more years tenure; age $35-55$ ) } \\
\hline Bailey & $\mathrm{F}$ & 11 & 38 & Non-profit - Marketing & New organization & $\sqrt{ }$ \\
\hline Briana & $\mathrm{F}$ & 10 & 38 & Aerospace - Contracts & Job change & \\
\hline Chet & M & 10 & 52 & Tax - C-suite & New organization & $\sqrt{ }$ \\
\hline CJ & M & 10 & 44 & Finance - Info. Technology & None & \\
\hline Denise & $\mathrm{F}$ & 16 & 55 & Telecom. - Sales & Job change & $\sqrt{ }$ \\
\hline Fred & M & 10 & 43 & Energy - Human Resources & Job change & $\sqrt{ }$ \\
\hline Heidi & $\mathrm{F}$ & 15 & 36 & Government - Operations & New supervisor & $\sqrt{ }$ \\
\hline Jeff & M & 9 & 40 & Professional Svcs- Consulting & New organization & \\
\hline Julianne & $\mathrm{F}$ & 25 & 53 & Finance - Operations & New supervisor & $\sqrt{ }$ \\
\hline Lynita & $\mathrm{F}$ & 14 & 55 & Public Health - Translation & None & $\sqrt{ }$ \\
\hline Maia & $\mathrm{F}$ & 16 & 49 & Science Svcs - Engineering & New organization & \\
\hline Megan & $\mathrm{F}$ & 9 & 41 & Technology - Business Ops. & New organization & $\sqrt{ }$ \\
\hline Rob & M & 17 & 46 & Technology - Project Mgmt & New organization & \\
\hline Roberto & M & 20 & 44 & Energy - Operations & None & \\
\hline Ronald & M & 23 & 53 & State Government - Housing & None & \\
\hline Sara & $\mathrm{F}$ & 22 & 51 & Higher Educ. - Office Mgr & New supervisor & $\sqrt{ }$ \\
\hline Sean & M & 14 & 44 & Technology - Sales & New organization & $\sqrt{ }$ \\
\hline Toby & M & 15 & 54 & Government Consulting & None & $\sqrt{ }$ \\
\hline Todd & M & 15 & 39 & Energy - Quality Control & Job change & $\sqrt{ }$ \\
\hline Trixie & $\mathrm{F}$ & 13 & 44 & Grocery - Human Resources & None & $\sqrt{ }$ \\
\hline Tyler & M & 16 & 49 & Transportation - Pilot & None & $\sqrt{ }$ \\
\hline Wade & M & 12 & 52 & Non-profit - CEO & None & $\sqrt{ }$ \\
\hline Winnie & $\mathrm{F}$ & 14 & 42 & Finance - Systems Mgmt & None & $\sqrt{ }$ \\
\hline \multicolumn{7}{|c|}{ Theoretical Sample } \\
\hline \multicolumn{7}{|c|}{ Seniors (age 60 or over) } \\
\hline Hal & M & 22 & 64 & Finance - Advisor & None & $\sqrt{ }$ \\
\hline Sonny & M & 23 & 60 & Energy - Info. Technology & None & \\
\hline Stan & M & 41 & 64 & Insurance - Sales & None & \\
\hline \multicolumn{7}{|c|}{ Newbies (age 21-25) } \\
\hline Braden & M & 1 & 25 & Education - Ph.D. Student & New organization & $\sqrt{ }$ \\
\hline Braxton & $\mathrm{F}$ & 1 & 22 & International Affairs & New organization & \\
\hline Desiree & $\mathrm{F}$ & 3 & 25 & Publishing - Assistant & Job change & $\sqrt{ }$ \\
\hline \multicolumn{7}{|c|}{ Job Hoppers (5 or less years tenure; age 35-55) } \\
\hline Carla & $\mathrm{F}$ & 5 & 42 & Non-profit - Fundraising & New organization & \\
\hline Marcie & $\mathrm{F}$ & 5 & 36 & Health - Instruction & New organization & $\sqrt{ }$ \\
\hline Rory & $\mathrm{M}$ & 5 & 47 & Finance - Consulting & New organization & $\sqrt{ }$ \\
\hline
\end{tabular}


Table 2

Fit Trajectories: Temporal Comparisons of Current Fit in terms of Past and Future Fit

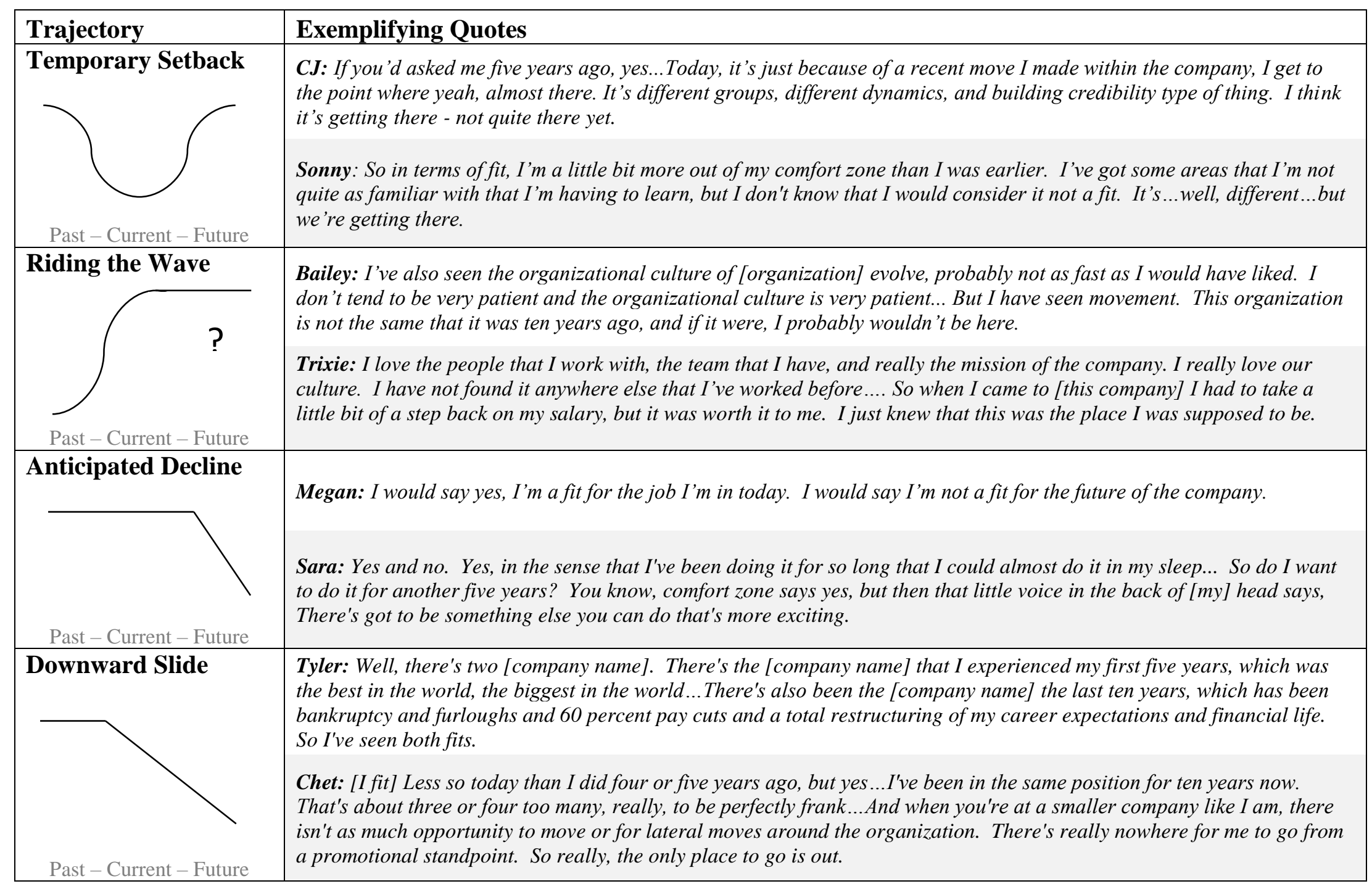


Table 3

Fit Themes: Identity-related Preferences for Fit Experiences

\begin{tabular}{|c|c|}
\hline Theme & Exemplifying Quotes \\
\hline Transactional & $\begin{array}{l}\text { CJ: It's either a question of, Hey. I've established this level. You either give me something bigger, or tell me you can't, and tell me } \\
\text { how you'll help me. I've done my part. Now you do your part. } \\
\text { Rob: It's just I gave it the shot, I did what...I've done what has been asked of me, and if there's not going to be some type of reciprocal } \\
\text { arrangement then it's time for me to go, it's time to move on. } \\
\text { Roberto: Well, do I want to stay in the company? As far as I can add value to an organization and the company gives me what I need, } \\
\text { yeah, of course. If not, I'll be moving somewhere else next. }\end{array}$ \\
\hline Instrumental & $\begin{array}{l}\text { Todd: So being in that environment, something new, something challenging - a new challenge - getting to know all of the regulatory } \\
\text { requirements, the community and state requirements, the different culture at this level, I really never thought much about it not being a } \\
\text { good fit because I was so focused on learning it and enjoying the daily challenges that I had. } \\
\text { Winnie: I like to learn about a lot of different things, and be not really a jack of all trades, but have the opportunity to learn about } \\
\text { different areas, and not be pigeonholed... we really need what you have over here and I look at it and go okay...that breadth and } \\
\text { diversity is interesting. It's no two days are the same, no two years are the same. It's cool. } \\
\text { Sean: They actually paired me up with this guy who had been there for a while, who was just the geekiest of geeks, nerd of nerds guy. } \\
\text { So I had this industry experience, and he had the technical background... He and I worked on the project together because he didn't } \\
\text { know the stuff I knew...It was a good team. }\end{array}$ \\
\hline \multirow{3}{*}{ Affiliative } & $\begin{array}{l}\text { Jeff: I enjoy that I feel needed. I knew all these things in positions - things that I could have done to improve my skill set and build my } \\
\text { resume, but for me, it - I just-I enjoy the working atmosphere. It's a comfort thing. I have good people around me. }\end{array}$ \\
\hline & $\begin{array}{l}\text { Lynita: I've been treated really so well. I'm respected by everybody. I feel that respect, too. And I just feel really comfortable here...I } \\
\text { feel like I have a home here. I feel appreciated. }\end{array}$ \\
\hline & Trixie: I've always felt like I'm home. It just feels right to me. \\
\hline Custodial & $\begin{array}{l}\text { Maia: I don't need to be in the spotlight. Some people really get something out of being in the spotlight. I really don't. I don't need it. } \\
\text { I could be totally behind the curtain and doing all the work, and as long as the person that I'm supporting recognizes that I'm doing } \\
\text { this, I don't need the world to know it. } \\
\text { Megan: I'm a pleaser in part...I'm extremely loyal. I've always been everyone's right-hand man...this is a key theme for me. I always } \\
\text { consider myself like the janitor. Every time there's a mess they ask me to go clean it up...I tell my boss this all the time, I'm the maid of } \\
\text { honor. I'm always the maid of honor. I'm not just a bridesmaid; I'm maid of honor. } \\
\text { Julianne. Whatever you need done, I'll just go and do it. I don't mean that to sound...boastful. That's not what it is. It's just like, how } \\
\text { can I help... I'll go help... and that's what I do...So what you're really getting is the whole work ethic and type of person you are. It's } \\
\text { not right for everybody. So that's why I say [I am a] caretaker. }\end{array}$ \\
\hline
\end{tabular}


Figure 1

Fitting as a Temporal Sensemaking Process ${ }^{a}$

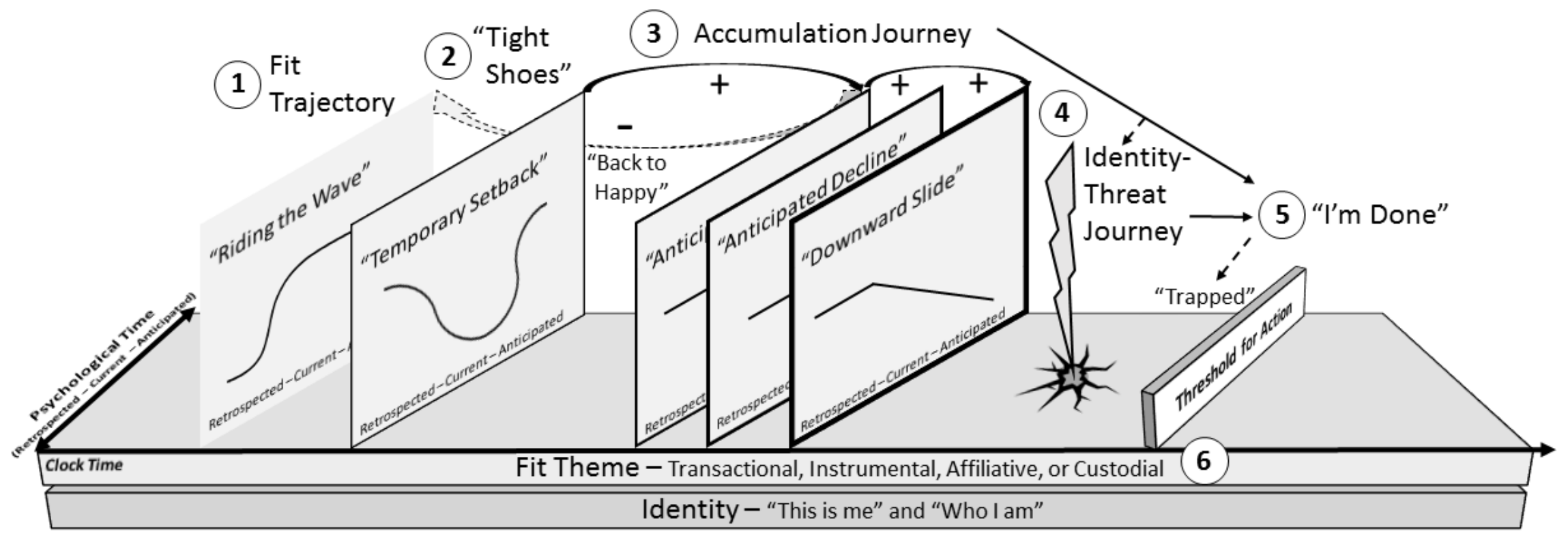

1 Each of these rectangles represents a momentary slice of clock time with forward and backward travel in psychological time. Triggered by events or being asked "do you fit?", each card represents a momentary fit assessment whereby individuals draw temporal comparisons with past and future fit. The resulting fit trajectory helps them to assess their current fit.

2 A border on the card reflects the presence of misfit. As misfit increases, the border darkens to reflect more frequent thoughts of ( $\mathrm{mis}$ ) fit.

3 The accumulation journey is initiated by recognition of misfit, with additional misfit events accumulating and being tolerated over clock time until reaching a threshold for action.

4 The identity threat journey is initiated by a realization or a "boom" event (represented as a lightning bolt) that challenges an individuals' beliefs or values, leading them to question "Who am I?"

5 "I'm done" reflects the end of both journeys. Either decisive action is taken to resolvemisfit, or the individual recognizes they are trapped and think about their ( $m i s)$ fit constantly.

6 Fit themes are one of four patterns of fit preferences enacted over time and reflecting an individual's beliefs and values.

a Figure adapted from Jaques (1982; Diagram 6.6, p. 98) 